\title{
THE PHYSICAL EDUCATION LESSON AS SEEN BY THE STUDENTS OF POLITEHNICA BUCHAREST
}

\author{
Oroles FLORESCU ${ }^{1 *}$, Mariana MEZEI ${ }^{1}$, Camelia BRANEȚ ${ }^{1}$, Adrian PRICOP $^{1}$ \\ ${ }^{1}$ Politehnica University, Department of Physical Education and Sports-Kinetotherapy, Bucharest, Romania \\ *Corresponding author: florescuoroles@yahoo.com
}

https://doi.org/10.35189/dpeskj.2020.59.2.7

\begin{abstract}
In the last years, the higher education system has been exposed to novelty by the diversification of teaching methods in physical education lessons and the implementation of a complex process of developing a new view on the curriculum. At the Politehnica University of Bucharest, educational activities must be part of each student's life and properly develop their psychomotor skills by improving their fitness level and wellbeing. The purpose of the study was to find out the opinions of students from the Politehnica University of Bucharest on both the physical education lesson and the ways of practising physical activities, which represents a modern vision of designing the lesson. The research was conducted on a sample of 741 students from the Politehnica University of Bucharest, of whom 322 female students and 419 male students. The study was carried out in two stages; first, between the $4^{\text {th }}$ and $15^{\text {th }}$ of November 2019, when students had to fill out a closed-ended questionnaire, and second, between the $18^{\text {th }}$ and $22^{\text {nd }}$ of November 2019, when the data were collected and processed. The results obtained from the assessment and interpretation of data represent a useful tool for designing and improving the new curriculum structure and, in order to also meet the demands of students, for introducing the multisport-type of physical education lesson and competitions in the first two years of study.
\end{abstract}

Keywords: students, physical education class, higher education, forms of organization.

\section{Introduction}

"The gap between what we say we want to do and what we are doing in practice has been and still is the main problem in physical education, as it is in many branches of education" (Mosston \& Ashworth, 2008, p. 8).

Engaging the student in the "sports lifestyle" in terms of sociopsychological development makes a perfect connection between practising physical movement and introducing the young person into society, knowing that physical education is a form of manifestation of human rights and has multiple influences on wellbeing and personal development.

The motor act triggers spontaneous reactions and special emotional experiences, reducing antisocial attitudes among youth. This can lead to a decrease in the occurrence of well-known diseases such as depression, anxiety, bulimia or anorexia, creating comfort in the development of personal skills and abilities in various fields. Socialisation through sports gives young people the opportunity to highlight their sports performance capacity during entertaining socio-competitive events.

Most developed countries have curriculum materials for physical education (Hardman \& Marshall, 2000; Pühse \& Gerber, 2005). They will often be specific syllabi, official policy statements, teacher resources, and similar; all of these documents can be thought of as texts that were written or produced (i.e. constructed) by someone (or a group of people) for some specific purpose (Rossi et al., 2009). 
Understanding how teachers promote physical activity through physical education is vital, as leading health and physical activity organizations have all emphasised the importance of providing physical activity in school physical education (Martin \& Kulinna, 2003).

Teachers/Specialists must have thorough knowledge of sports science to meet the new trends in the development of this social segment, providing new theoretical models that can shape the future of physical education and sports.

The research programme at San Diego State University reveals the critical influence that teachers have on student behaviour, as it has consistently demonstrated that the students of physical education teachers who employ a physical-activity oriented curriculum are more physically active than students who are taught by teachers with less professional preparation (McKenzie et al., 1993; McKenzie et al., 1995; McKenzie et al., 1997; McKenzie et al., 2000; McKenzie et al., 2001; Sallis et al., 1997).

Several studies show a decrease in sports activity during the transition from adolescence to adulthood, from high school to university due to the curricular area that undergoes obvious changes caused by the fact that each university has its own autonomy. The insufficiency of this kind of activity in students has multiple effects on their health status and personality development (Brettschneider, 2004; Kilpatrick et al., 2005).

Specialists such as Kulik et al. (2019) believe that for students to benefit from increased amounts of physical activity, schools need to offer quality physical education programmes that provide them with opportunities to meet the recommended daily amount of physical activity.

According to studies (Dragnea et al., 2006), the practice of physical exercise has existed since ancient times, going through several stages of development. A first stage focused on physical education for health, the second aimed at the relationship between physical education and complete education (nutrition, motor skills, moral qualities/ understanding and intellectual education/ learning), and the third brought as novelty the practice of ball games. This type of movement becomes the main objective of the physical education and sport lesson, contributing to "mind" education (intellectual activity) and self-attitude development, encouraging social interaction and thus getting easiness in self-expression.

In the last years, the higher education system has been exposed to novelty by the diversification of teaching methods in physical education lessons and the implementation of a complex process of developing a new view on the curriculum.

Romanian theorists (Hora et al., 2019) state that this school subject has a modest place in the national curriculum due to its confrontation with several negative factors that hinder the improvement and development of the physical education and sport lesson. The low number of classes per week provided in the curriculum, inadequate funding and material support, lack of solutions offered by the system, all of this compels the specialist to present methods, techniques and means that can lead to continuous improvement.

At the Politehnica University of Bucharest (UPB), educational activities must be part of each student's life and properly develop their psychomotor skills by improving their fitness level and wellbeing.

In Romania, grassroots sport has undergone significant expansion due to public awareness of the important connection between the practice of physical exercise and the high level of health among the population. Therefore, this study could be conducted on the basis of well- 
founded knowledge about the benefits of sport on the human body. The general objective was to find out the attitudes towards and preferences of students for physical and sports activities, their involvement in practising these activities in terms of duration and frequency.

Giving students the freedom to express their opinions in our study allowed us to choose the most varied types of lessons, starting from the classic one based on links with independent objectives to the single-sport or mixed and multisport lesson. Practising several sports during one lesson and ending with a competitive game leads to the emergence of emotional states that stimulate more and even go beyond the student's state of psychological comfort.

According to Zohrabi (2013), questionnaires are doubtless one of the primary sources of obtaining data in any research endeavour. However, the critical point is that, when designing a questionnaire, the researcher should ensure that it is "valid, reliable and unambiguous" (Richards \& Schmidt, 2002, p. 438).

A questionnaire is only as good as the questions it asks; therefore, questionnaires should be as well designed as possible, with questions as precise and as easy to respond as possible (Hyman \& Sierra, 2016).

This type of closed-ended questions is very helpful for designing and developing the study method in the form of a questionnaire. On the one hand, we get a higher response rate from the investigated subjects due to the ease of responding to questions and, on the other hand, the responses can be easily analysed statistically. The results can create a number of school educational opportunities.

\section{Methodology}

\section{Research purpose}

The purpose of the study was to find out the opinions of students from the Politehnica University of Bucharest on both the physical education lesson and the ways of practising physical activities, which represents a modern vision of designing the lesson.

Gender-based identification of the bio-psycho-motor needs of future engineers could lead to real findings. Relying on these findings, new programmes for the optimisation and improvement of sports lessons could be created.

\section{Research methods}

The research methods used were: scientific documentation (to establish issues and trends), questionnaire survey (to highlight decisive behavioural factors), mathematical and statistical method, graphical method. The data were recorded, ordered and statistically processed to be presented in the form of tables and graphs that show the real situation described in this study.

\section{Research subjects}

The research was conducted on a sample of 741 students from the Politehnica University of Bucharest, aged between 19 and 23 years, of whom 322 female students and 419 male 
students. As a non-profit university, first and second year students that belong to one of the 15 UPB faculties follow the same structure and undergo the same type of coaching and training during sports lessons. The subjects of this study were randomly selected, their number varying from one faculty to another. The respondents were instructed as regards the way of survey completion and were provided with optimal circumstances for the good conduct of the study.

\section{Instruments}

The questionnaire applied contains closed-ended questions (that require simple responses), the student having a single choice among several options. The paper/pencil questionnaire was anonymous, and student participation in the research was voluntary.

Seliger and Shohamy (1989) believe that closed-ended questionnaires are more efficient because of their ease of analysis.

In order to build the questionnaire items, we have started from the assumption that active participation in sports classes can support the development of young people. The questionnaire administered to the 741 respondents was made up of seven closed-ended items that were analysed and interpreted.

The seven items are:

1. What would be the optimal time to be allocated for the physical education and sport lesson in the curriculum?

a. Weekly in semester 1

b. Weekly in semesters 1 and 2

c. Weekly in semesters 1 to 4

d. Once every two weeks in semester 1

e. Once every two weeks in semesters 1 and 2

f. Once every two weeks in semesters 1 to 4

2. Choose a form of organization of the physical education and sports activity that you consider to be optimal:
a. Multisport lesson
b. Single-sport lesson
c. Multisport lesson and competitions
d. Single-sport lesson and competitions

3. Choose the type of sport you would like to practise during physical education and sport lessons:
a. individual sports
b. team sports

4. Which individual sport would you like to practise during physical education and sport lessons?
a. table tennis
b. badminton
c. chess
d. athletics
e. gymnastics/dance 
5. Which team sport would you like to practise during physical education and sport lessons?
a. football
b. handball
c. basketball
d. volleyball

6. Do you consider it appropriate to implement programmes aimed at optimising and improving the quality of life in the physical education and sport lesson?
a. yes
b. no

7. Which of the following benefits of practising physical exercise is a priority for you?
a. health
b. physical appearance
c. psycho-emotional issues

\section{Procedure}

The study was carried out in two stages: first, between 4 and 15 November 2019, when students had to fill out a closed-ended questionnaire, and second, from 18 to 22 November 2019, when the data were collected and processed.

\section{Results}

The opinions of students in technical higher education referred to their preferences for/ attitudes towards the physical education and sport lesson, the time allocated to leisure physical and sports activities and the benefits of physical exercise on their bodies. The collected data were summarised, analysed and graphically represented in the following tables and figures.

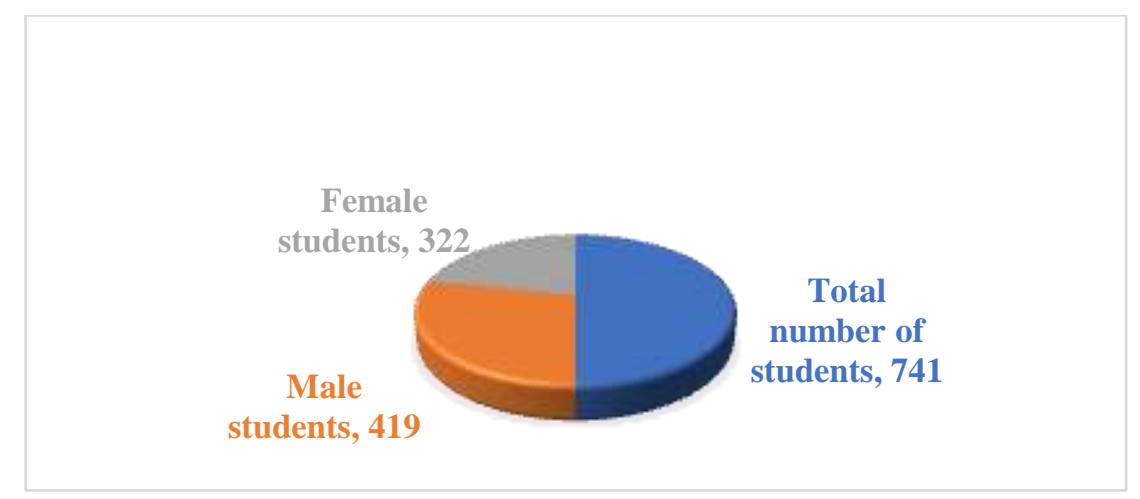

Figure 1. Gender distribution of respondents

As can be seen in Figure 1, a clear picture of participating subjects is provided in terms of gender distribution. Thus, the investigated sample highlights the large number of male students in technical faculties. This distribution helps us make an accurate analysis of the 
final result for each item.

Considering the diversification existing in the Politehnica University of Bucharest, which results from the fact that each faculty designs its own curriculum, the number of physical education and sport classes is also much diversified. Table 1 shows the opinions of students regarding the first item of the questionnaire, which has a large variation in the choice of a response. All these versions are officially found in the UPB curricula.

Table 1. Statistical data on students' opinions regarding the time to be allocated for the physical education and sport lesson in the curriculum

\begin{tabular}{lcccc}
\hline $\begin{array}{c}\text { Time to be allocated for the physical } \\
\text { education and sport lesson }\end{array}$ & $\begin{array}{c}\text { Male } \\
\text { students }\end{array}$ & $\begin{array}{c}\text { Male students } \\
\text { (percent) }\end{array}$ & $\begin{array}{c}\text { Female } \\
\text { students }\end{array}$ & $\begin{array}{c}\text { Female students } \\
\text { (percent) }\end{array}$ \\
\hline Weekly in semester 1 & 56 & 13.36 & 49 & 15.21 \\
Weekly in semesters 1 and 2 & 118 & 28.16 & 105 & 32.60 \\
Weekly in semesters 1 to 4 & 205 & 48.92 & 122 & 37.88 \\
Once every two weeks in semester 1 & 16 & 3.81 & 25 & 7.76 \\
Once every two weeks in semesters 1 and 2 & 13 & 3.10 & 10 & 3.10 \\
Once every two weeks in semesters 1 to 4 & 11 & 2.62 & 11 & 3.41 \\
\hline
\end{tabular}

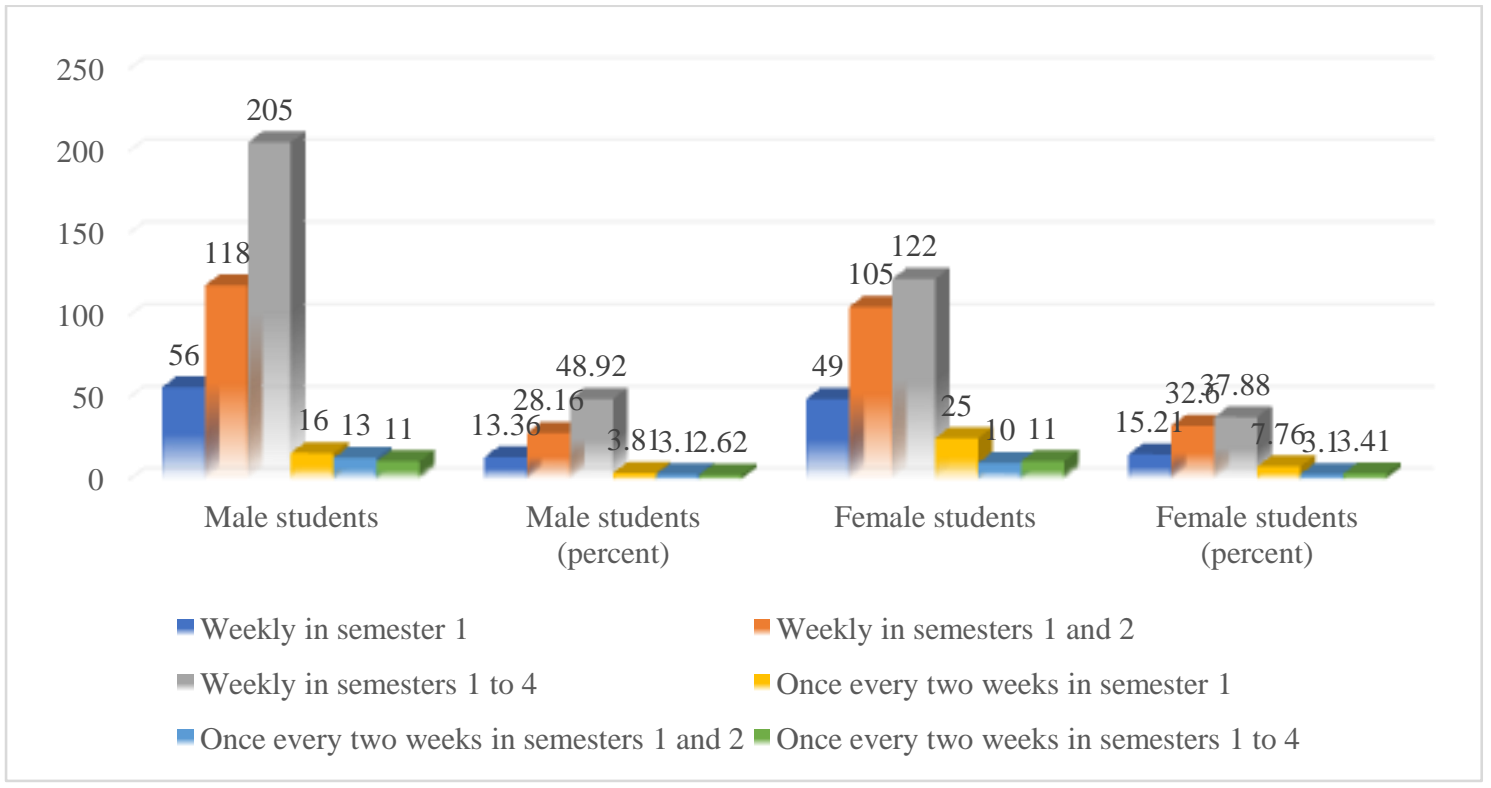

Figure 2. Distribution of students' opinions regarding the time to be allocated for the physical education and sport lesson in the curriculum

The wide variety of responses to this item has drawn our attention to two results, $48.92 \%$ and $37.88 \%$, which are the highest percentages recorded by the entire sample, the investigated students opting for weekly participation in physical education and sport lessons during each semester, in both years of study. A percentage of $28.16 \%$ of male students and $32.6 \%$ of female students want to participate in this type of activity once a week, only in the first year of study. A low number of students, $13.36 \%$ male and $15.21 \%$ female, prefer one lesson per week only in semester 1 . The percentage of students who want to participate in physical education lessons once every two weeks is insignificant. 
The opinions of students clearly show that both male and female respondents want to benefit from longer time for participation in physical and sport activities in an organized setting.

Exploring relevant concepts such as socialisation or individual development of the young generation, we opted to also introduce in the study the young student's opinion regarding the form of organization of the physical education and sport lesson. Statistical data summarised in Table 2 confirm that the new generation tends to demonstrate their physical qualities and abilities by achieving high performance during socio-competitive activities.

Table 2. Statistical data on students' opinions regarding the form of organization of the physical education and sports activity

\begin{tabular}{lcccc}
\hline \multicolumn{1}{c}{ Lesson type } & $\begin{array}{c}\text { Male } \\
\text { students }\end{array}$ & $\begin{array}{c}\text { Male students } \\
\text { (percent) }\end{array}$ & $\begin{array}{c}\text { Female } \\
\text { students }\end{array}$ & $\begin{array}{c}\text { Female students } \\
\text { (percent) }\end{array}$ \\
\hline Multisport lesson & 141 & 33.65 & 131 & 40.68 \\
Single-sport lesson & 48 & 11.45 & 33 & 10.24 \\
Multisport lesson and competitions & 199 & 47.49 & 142 & 44.09 \\
Single-sport lesson and competitions & 31 & 7.39 & 16 & 4.96 \\
\hline
\end{tabular}

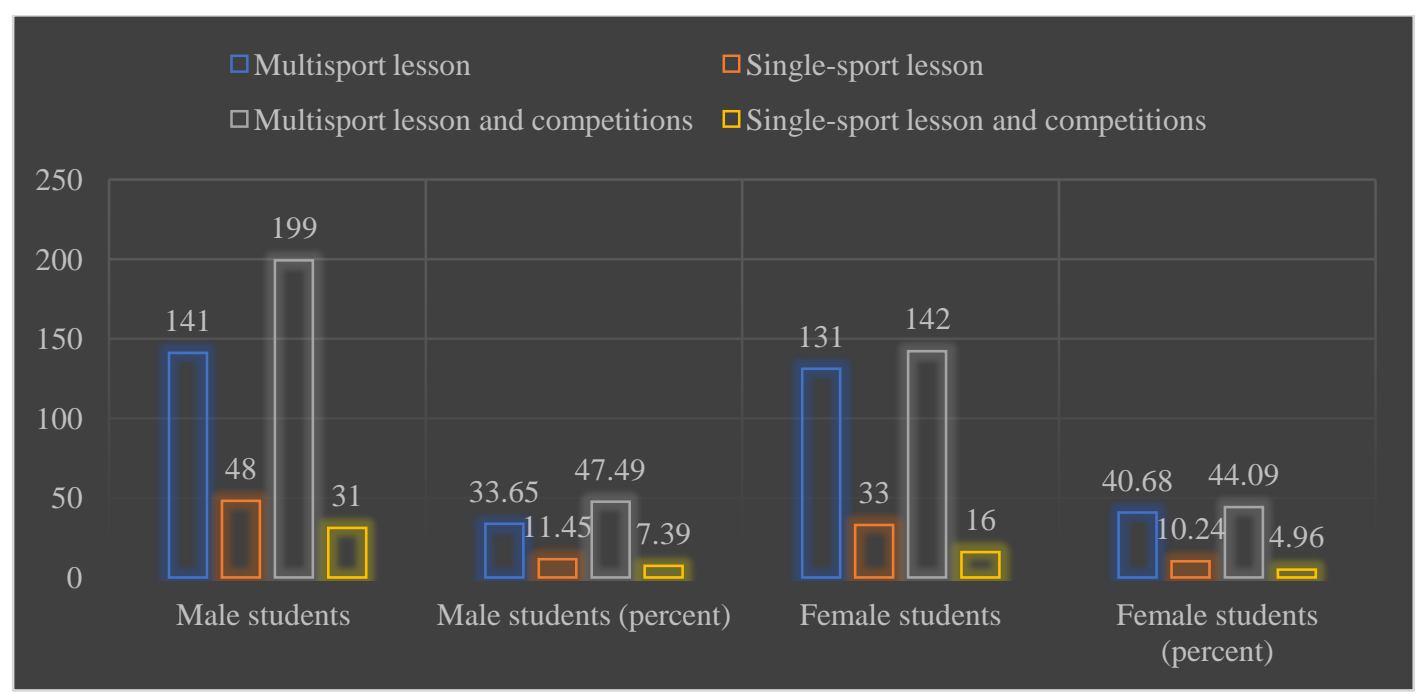

Figure 3. Distribution of students' opinions regarding the form of organization of the physical education and sports activity

Analysing the graph in Figure 3, it can be noted that almost $50 \%$ of male respondents and $44.09 \%$ of female respondents have opted for multisport lessons and competitions, considering them as optimal for harmonious physical development in psychomotor terms. Not far behind is another category of respondents for whom multisport lessons are a priority, statistical data showing a percentage of $33.65 \%$ among male students and a higher percentage, $40.68 \%$, among female students. Single-sport lessons and single-sport lessons and competitions are the least chosen by male and female students from the Politehnica University of Bucharest, indicating that they do not like practising a single sports branch during the physical education and sport lesson. 
Analysing and making a correlation between the options of male and female respondents, we can see that their choices are similar as regards the form of organization of the physical education and sports activity.

In order to create a successful framework for this type of activity, we must also take into account the preferences/options of students, mainly aiming to make them reach a good emotional state based on high self-esteem. This way of addressing sports makes a strong connection between physical activity and an important psychological component consisting of attitudes, opinions and values.

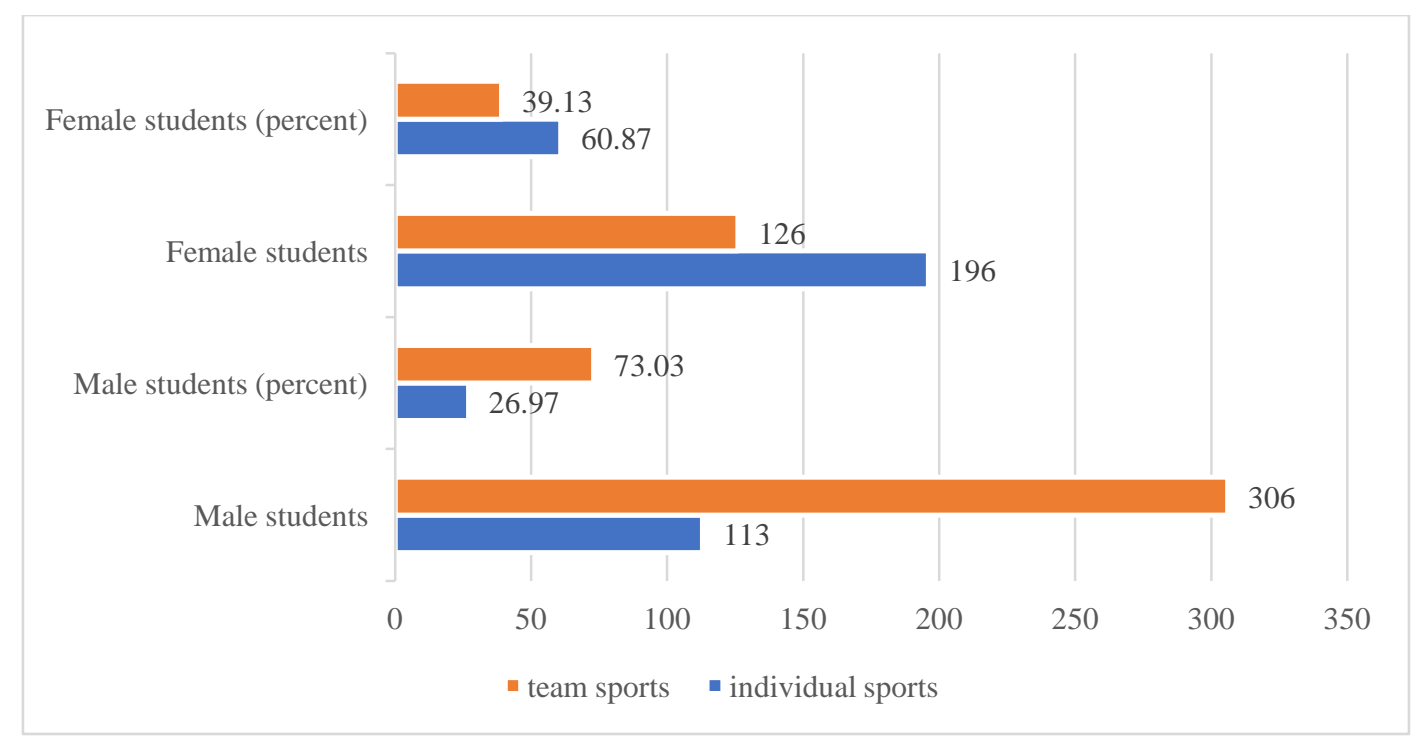

Figure 4. Distribution of favourite sports in physical education and sport lessons

In order to have a clearer picture of the responses, we analysed the distribution of subjects by gender. Statistical data in Figure 4 indicate a large variation in options for this item. This time, there are differences between the two genders, $73.03 \%$ of male students choosing the practice of team sports, and $60.87 \%$ of female preferring individual sports.

As regards the differences of only $26.97 \%$ for males and $39.13 \%$ for females, they are not significant to influence the design of new programmes. These differences derive from the characteristics and personalities of each gender.

The motivation of male students to practise a sport is: adversity, desire to win, desire to show courage, interest in competition, or solving critical situations. The motivation of female students is the desire of self-assertion by making best use of their own abilities. 


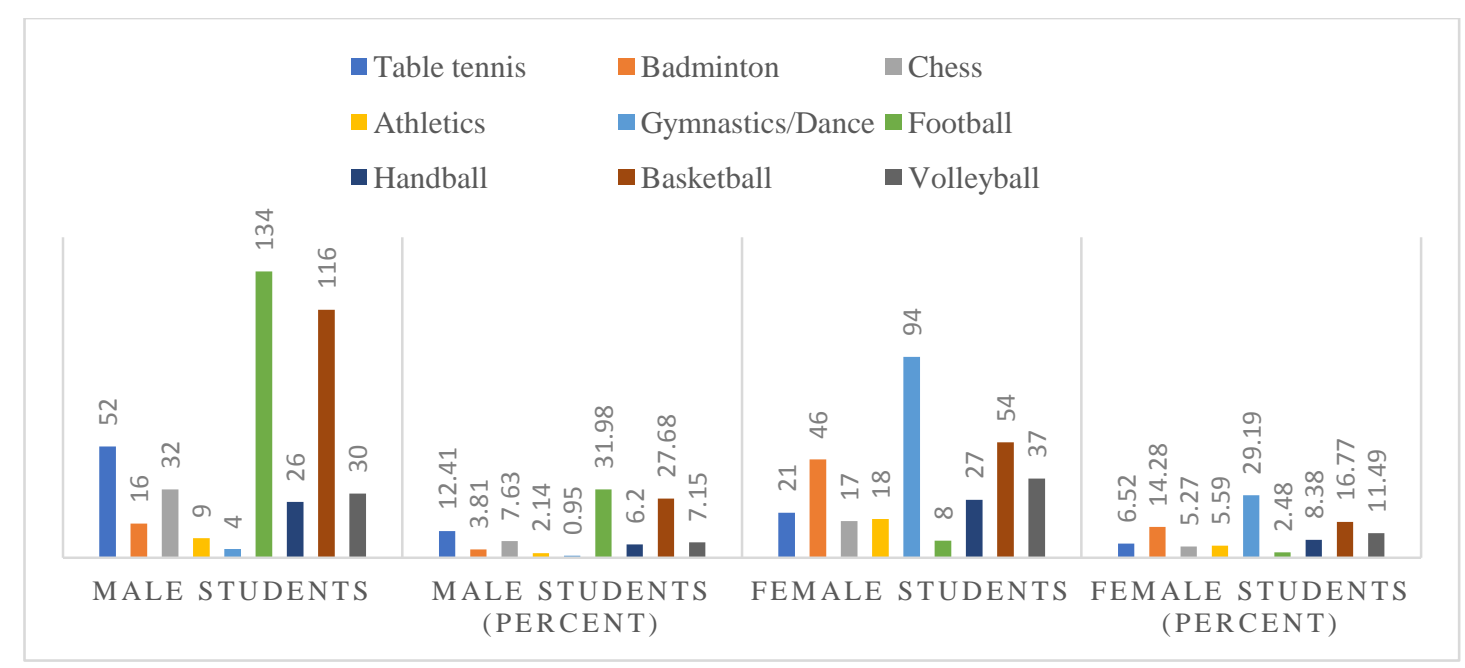

Figure 5. Distribution of values regarding the preferences for practising a branch of sport

Research data for items 4 and 5 confirm once again that female students are not fond of socialisation within group activities, 94 of responses to the question about the sport they would like to practise being in favour of gymnastic branches, namely aerobics and dance. Instead, male students would like to practise football and basketball, with the percentages of $31.98 \%$ and $27.68 \%$, respectively.

Figure 5 graphically shows all sports branches provided in the physical education and sport curricula of the Politehnica University of Bucharest, but also encountered in official competitions organized under the aegis of Politehniada. It can be noted that no percentage is close to $50 \%$ in favour of a particular sport, but the percentages are distributed among all branches of sport.

A percentage close to $100 \%$ is found in item 6 of the questionnaire, where almost all responses are positive, therefore in favour of implementing new programmes aimed at optimising and improving the quality of life. This opinion reflects the phenomena and changes in modern society, the interest of young people in everything that is new and innovative. It also reveals their openness to methods and means as varied as possible, which can intervene in the training process of the individual by maintaining aesthetic standards and increasing efficiency of the time used.

Considering that the participation of adolescents and young people in performance sports, as a social phenomenon in contemporary societies, has significantly decreased, we can conclude that the young generation is not willing to go beyond their comfort zones. So, performance sport is not considered an opportunity for choosing a lifestyle, even if it leads to the creation of universal sports values. The young people's view of sport and the important benefits of the motor act is very well reflected in the data shown in Table 3. 
Table 3. Statistical data on the benefits of physical exercise as seen by students

\begin{tabular}{lcccc}
\hline \multicolumn{1}{c}{ Benefits of physical exercise } & $\begin{array}{c}\text { Male } \\
\text { students }\end{array}$ & $\begin{array}{c}\text { Male students } \\
\text { (percent) }\end{array}$ & $\begin{array}{c}\text { Female } \\
\text { students }\end{array}$ & $\begin{array}{c}\text { Female students } \\
\text { (percent) }\end{array}$ \\
\hline Health & 243 & 57.99 & 147 & 45.65 \\
Physical appearance & 170 & 40.57 & 173 & 53.72 \\
Psycho-emotional issues & 6 & 1.44 & 2 & 0.63 \\
\hline
\end{tabular}

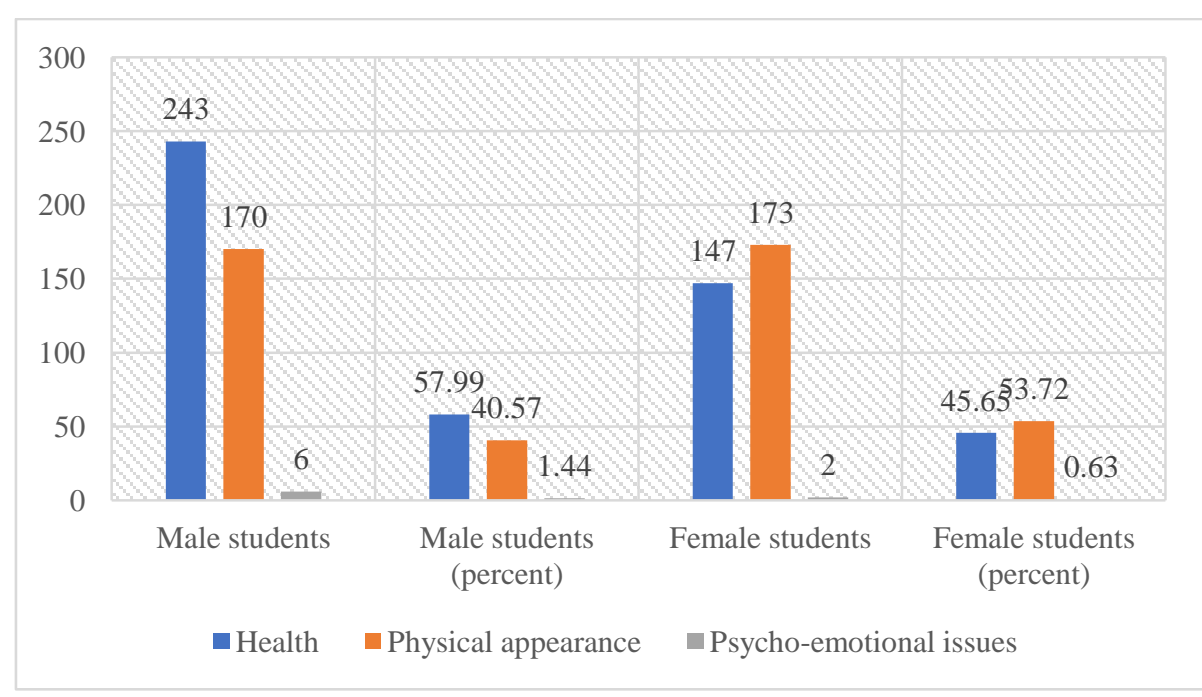

Figure 6. Distribution of values regarding the benefits of physical exercise as seen by students

For female respondents, the percentage of $53.72 \%$ indicates that physical exercise has as main objective the formation and development of a proper physical appearance, and the remaining $45.65 \%$ consider that the benefits of the motor act consist in reaching a state of comfort and good health. This last item also shows differences between genders.

Male subjects agree to the idea that sport as a lifestyle leads to improved health status, the percentage of $57.99 \%$ confirming this by the data that are graphically shown in Figure 6. Only $1.44 \%$ of male students and $0.63 \%$ of female students responded in favour of psychoemotional issues.

\section{Conclusion}

The identification of trends in the attitudes of students from technical faculties towards physical and sports activities, but also of their preferences in this matter, has led us to focus on their main reasons to participate in this type of activity. The concept of connection between physical appearance and lifestyle, between movement and health, confirms the increasing interest in socialisation through sports, maintaining and improving health, as well as in bodily appearance.

The sample participating in this study has understood that modern physical exercise facilitates the vision of optimal body evolution, which mainly aims at wellbeing, harmonious physical development, improved motor skills and educating motor skills that lead to ideal balance. 
Correct information about the benefits of physical exercise on the body and the use of methods and means to prevent possible negative effects can positively influence the young generation's lifestyle throughout their lives.

Regarding the quality/quantity ratio during physical education and sport classes, we noted the young people's orientation towards modern values. In search of optimal solutions, we need to consider the opinions of students in order to develop new accessible and attractive programmes.

Introducing competitions in the physical education and sport lesson or a wider range of options in terms of sports branches addressed can be a determining factor for the active participation of students in physical education and sport classes.

The results obtained from the assessment and interpretation of data represent a useful tool for designing and improving the new curriculum structure and, in order to also meet the demands of students, for introducing the multisport-type of physical education lesson and competitions in the first two years of study.

The preliminary data collected following the survey offer us the possibility to create new programmes that meet the demands of students. This will lead to the improvement of their psychomotor abilities.

\section{Authors' Contributions}

All authors have equally contributed to this study and should be considered as main authors.

\section{References}

Brettschneider, W.-D. (2004). Study on young people's lifestyles and sedentariness and the role of sport in the context of education and as a means of restoring the balance. In European Report "Young People's Lifestyles and the Role of Sport Involvement". Brussels: European Commission. http://ec.europa.eu/sport/library/documents/c1/doc374_en.pdf

Dragnea, A., Bota, A., Stănescu, M., Teodorescu, S., Șerbănoiu, S., \& Tudor, V. (2006). Educație fizică și sport - Teorie și didactică [Physical education and sport - Theory and didactics]. București: FEST.

Hardman, K., \& Marshall, J. (2000). World-wide survey of the state and status of school physical education: The final report to the International Olympic Committee. Manchester: University of Manchester.

Hora, A., Ciolcă, C., \& Negulescu, I. (2019). Strategies for involving students in the physical education lesson. The European Proceedings of Social and Behavioural Sciences, LV, 473-481. https://dx.doi.org/10.15405/epsbs.2019.02.59

Hyman, M. R., \& Sierra, J. J. (2016). Open- versus close-ended survey questions. NMSU Business Outlook, 14(2), 1-5.

Kilpatrick, M., Hebert, E., \& Bartholomew, J. (2005). College students' motivation for physical activity: Differentiating men's and women's motives for sport participation and exercise. Journal of American College Health, 54(2), 87-94.

https://doi.org/10.3200/JACH.54.2.87-94 
Kulik, K. S., Brewer, H. J., \& Baker, J. S. (2019). The effect of demographic factors on the implementation of quality physical education. Journal of Physical Education and Sports Management, 6(2), 1-13. https://doi.org/10.15640/jpesm.v6n2a1

Martin, J. J., \& Kulinna, P. H. (2003). The development of a physical education teachers' physical activity self-efficacy instrument. Journal of Teaching in Physical Education, 22(2), 219-232. https://doi.org/10.1123/jtpe.22.2.219

McKenzie, T. L., Feldman, H., Woods, S. E., Romero, K. A., Dahlstrom, V., Stone, E. J., Strikmiller, P. K., Williston, J. M., \& Harsha, D. W. (1995). Children's activity levels and lesson context during third-grade physical education. Research Quarterly for Exercise and Sport, 66(3), 184-193. https://doi.org/10.1080/02701367.1995.10608832

McKenzie, T. L., Marshall, S. J., Sallis, J. F., \& Conway, T. L. (2000). Student activity levels, lesson context, and teacher behavior during middle school physical education. Research Quarterly for Exercise and Sport, 71(3), 249-259. https://doi.org/10.1080/02701367.2000.10608905

McKenzie, T. L., Sallis, J. F., Faucette, B., Roby, J. J., \& Kolody, B. (1993). Effects of a curriculum and in-service program on the quantity and quality of elementary physical education class. Research Quarterly for Exercise and Sport, 64(2), 178-187. https://doi.org/10.1080/02701367.1993.10608795

McKenzie, T. L., Sallis, J. F., Kolody, B., \& Faucette, F. N. (1997). Long-term effects of a physical education curriculum and staff development program: SPARK. Research Quarterly for Exercise and Sport, 68(4), 280-291. https://doi.org/10.1080/02701367.1997.10608009

McKenzie, T. L., Stone, E. J., Feldman, H. A., Epping, J. N., Yang, M., Strikmiller, P. K., Lytle, L. A., \& Parcel, G, S. (2001). Effects of the CATCH physical education intervention: Teacher type and lesson location. American Journal of Preventative Medicine, 21(2), 101-109. https://doi.org/10.1016/s0749-3797(01)00335-x

Mosston, M., \& Ashworth, S. (2008). Teaching physical education. https://pendor.unublitar.ac.id/wp-content/uploads/2019/08/Muska-Mosston-TeachingPhysical-Education.pdf.pdf

Pühse, U., \& Gerber, M. (2005). (Eds.) International comparison of physical education. Oxford: Meyer \& Meyer Sport.

Richards, J. C., \& Schmidt, R. (2002). Longman dictionary of language teaching and applied linguistics $\left(3^{\text {rd }}\right.$ ed.). London: Longman.

Rossi, T., Tinning, R., McCuaig, L., Sirna, K., \& Hunter, L. (2009). With the best of intentions: A critical discourse analysis of physical education curriculum materials. Journal of Teaching in Physical Education, 28(1), 75-89. https://doi.org/10.1123/jtpe.28.1.75

Sallis, J. F., McKenzie, T. L., Alcaraz, J. E., Kolody, B., Faucette, N., \& Hovell, M. F. (1997). The effects of a 2-year physical education program (SPARK) on physical activity and fitness in elementary school students. American Journal of Public Health, 87(8), 1328-1334. https://doi.org/10.2105/AJPH.87.8.1328

Seliger, H. W., \& Shohamy, E. (1989). Second language research methods. Oxford: OUP.

Zohrabi, M. (2013). Mixed method research: Instruments, validity, reliability and reporting findings. Theory and Practice in Language Studies, 3(2), 254-262.

http://dx.doi.org/10.4304/tpls.3.2.254-262 